\title{
A LEI N. 775, DE 1949, E AS CONSEQUÊNCIAS PARA A FORMAÇÃO DA ENFERMEIRA CEARENSE
}

\author{
LAW NO. 775, OF 1949, AND THE CONSEQUENCES \\ FOR THE FORMATION OF NURSES OF CEARÁ
}

\section{LA LEY N.775, DE 1949, Y LAS CONSECUENCIAS PARA LA FORMACIÓN DE LA ENFERMERA CEARENSE}

\author{
Roberlandia Evangelista Lopes ${ }^{1}$ \\ Silvia Maria Nóbrega-Therrien ${ }^{2}$ \\ Carlos Romualdo de Carvalho e Araújo ${ }^{3}$
}

Como citar este artigo: Lopes RE, Nóbrega-Therrien SM, Araújo CRC. A Lei n. 775, de 1949, e as consequências para a formação da Enfermeira cearense. Rev baiana enferm. 2018;32:e26736.

Objetivo: analisar as consequências da Lei n. 775, de 6 de agosto de 1949, ou nova ordem, na formação e prática da Enfermeira cearense nos anos de 1949 a 1961. Método: estudo histórico, com abordagem qualitativa, que "enxerga" as fontes utilizadas por meio da História Cultural. O instrumento de coleta de dados utilizado foi a entrevista. Resultados: depreendeu-se das fontes escritas e orais oriundas da Escola de Enfermagem São Vicente de Paulo de Fortaleza, Ceará, Brasil, que a instituição da profissão de Auxiliar de Enfermagem promoveu uma "nova ordem" no campo do cuidado e gerou consequências na formação e na função exercida pela Enfermeira, seu reconhecimento social, identitário e no campo de poder. Conclusão: a Lei n. 775, de 1949, teve como consequência, para a prática da Enfermeira, a transformação da formação e do objeto de atuação dessa profissional não apenas no estado do Ceará como também em todo o Brasil.

Descritores: Decreto-Lei. História da Enfermagem. Pesquisa em Enfermagem.

Objective: analyze the consequences of Law No. 775, dated August 6, 1949, or a new order, in the training and practice of the Nurse in Ceará from 1949 to 1961. Method: historical study using a qualitative approach that "sees" the sources used through Cultural History. The instrument of data collection used was the interview. Results: it was inferred from written and oral sources from the São Vicente de Paulo Nursing School in Fortaleza, Ceará, Brazil, that the institution of Nursing Assistant promoted a "new order" in the field of care and generated consequences in the formation and in the role played by the Nurse, and in their social recognition, identity and in the field of power. Conclusion: Law No. 775, of 1949, had as a consequence, for the Nurses' practice, the transformation of the training and the object of these professionals to work not only in the state of Ceará but also throughout Brazil.

Descriptors: Decree-Law. Nursing History. Nursing Research.

Objetivo: analizar las consecuencias de la Ley n. 775, de 6 de agosto de 1949, o nuevo orden, en la formación y práctica de la Enfermera cearense en los años de 1949 a 1961. Método: estudio histórico, con abordaje cualitativo, que "ve" las fuentes utilizadas por medio de la Historia Cultural. El instrumento utilizado para recolectar los datos, fue la entrevista. Resultados: se dedujo a través de fuentes escritas y orales oriundas de la Escuela de Enfermería São Vicente de Paulo de Fortaleza, Ceará, Brasil, que el establecimiento de la profesión de Auxiliar de Enfermería

\footnotetext{
Enfermeira. Doutora em Educação. Docente do Centro Universitário UNINTA. Sobral, Ceará, Brasil. roberlandialopes@hotmail.com

Enfermeira. Doutora em Sociologia da Educação. Docente da Universidade Estadual do Ceará. Fortaleza, Ceará, Brasil.

Enfermeiro. Sobral, Ceará, Brasil. romualdocrca@hotmail.com
} 
promovió un "nuevo orden" en el campo del cuidado y generó consecuencias en la formación y en la función ejercida por la Enfermera, su reconocimiento social, identidad y en el campo de poder. Conclusión: a Ley n.775, de 1949, tuvo como consecuencia, para la práctica de la Enfermera, la transformación de la formación y del objeto de actuación de esta profesional no solo en Ceará sino también en todo Brasil.

Descriptores: Decreto-Ley. Historia de la Enfermería. Investigación en Enfermería.

\section{Introdução}

A Lei n. 775, de 6 de agosto de 1949, impõe uma "nova ordem"(1) no momento em que cria outra categoria ocupacional na enfermagem, a Auxiliar de Enfermagem. Esta profissional passa, oficialmente, a trabalhar na área da saúde junto com a Enfermeira "diplomada", sobretudo no contexto hospitalar, bem como a dividir com ela (Enfermeira) o mesmo espaço de formação e campo de atuação. Nesses termos, identifica-se a Lei n. 775, de 6 de agosto de 1949, como um "divisor de águas" na profissão da Enfermeira, tendo em vista que legaliza a cisão formativa do cuidado em enfermagem entre duas categorias da profissão.

Essa legalização implica em uma diversidade de consequências que, ao longo deste artigo, vão sendo evidenciadas. Uma delas é que esse cuidado passa a ser praticamente "cedido" aos poucos e, posteriormente, é praticamente "restrito" ao Auxiliar de Enfermagem, enquanto que à Enfermeira cabe, de forma crescente, preponderantemente, atividades de supervisão dessa função.

Esse fato é reforçado com o passar dos anos, em especial em virtude das condições estruturais dos mercados brasileiro e cearense, no caso, e da escassez de pessoal qualificado para realizar o cuidado. A questão da mão de obra na profissão, na década de 1940, começava a gerar um sério problema para a União e para os estados responderem às demandas crescentes que surgiam em busca de assistência de enfermagem, pois, nessa época, havia cerca de 2.600 Enfermeiras atuando no país, número irrisório em relação à população nacional $^{(2)}$. As epidemias foram também motivo e fatores que contribuíram para essa situação, uma vez que estavam entre as prioridades da agenda de saúde no Brasil nesse período ${ }^{(3)}$.

Outros fatores também contribuíram para a promulgação da citada lei ou da "nova ordem", dentre os quais assinala-se: influência de outros países, em especial da Inglaterra, quanto à concepção do trabalho e suas relações e segmentações, no caso, a divisão social do trabalho na Enfermagem, além da aliança que se fortalecia entre o Estado e a Igreja no Brasil, notadamente favorecendo a presença maciça das congregações e suas religiosas nos hospitais e nas Santas Casas.

Assim, considera-se que a investigação proposta é de natureza inovadora, pois, mesmo pesquisando temas provenientes de um passado recente, o faz apoiado em uma base mais abrangente e oriunda de outras fontes de descobertas capazes de evidenciar outros fatos e entendimentos para o conhecimento das consequências da Lei n. 775, de 1949, para a profissão da Enfermeira. A forte e oficial cisão na formação e, consequentemente, na prestação do cuidado - a função maior e a essência da profissão -, que passa a ser executado, sobretudo, pela Auxiliar de Enfermagem, é uma das principais consequências desse novo regramento.

O interesse por esse campo de pesquisa surgiu com a imersão dos pesquisadores no desenvolvimento do Núcleo de Documentação, Informação, História e Memória da Enfermagem no Ceará (NUDIHMEn) ${ }^{4}$, que vem contribuído para o desenvolvimento de estudos sobre a enfermagem cearense. Logo, a pesquisa justifica-se por trazer à tona a formação na enfermagem e para se entender o que estava implícito na condução de sua trajetória profissionalizante. Entende-se que 
a história dessa profissão não segue um percurso linear, mas é fruto de resultados, em sua maioria conflituosos, que envolvem um jogo de forças e de poderes no qual quem ganha (quase sempre) é o grupo que domina.

A pesquisa traz, ainda, inovação, ao contribuir para suprir lacunas desta temática, como pesquisa no campo da produção científica na área do ensino da enfermagem, tendo como foco as repercussões da Lei n. 775, de 1949, para a profissão da Enfermeira. O estudo do estado da arte desse objeto de investigação possibilitou a obtenção de importantes constatações ${ }^{(5)}$.

Este estudo tem por objetivo analisar as consequências da Lei n. 775, de 6 de agosto de 1949, na formação e na prática da Enfermeira cearense, nos anos de 1949 a 1961.

\section{Método}

Estudo histórico, de natureza qualitativa. Optou-se pela História Cultural (HC) como referencial teórico-metodológico para desenvolver esta investigação, especialmente focando o relacionamento da $\mathrm{HC}$ com as fontes e seu tratamento. A HC foi essencial para o entendimento do objeto estudado, uma vez que a questão epistemológica dessa postura histórica estaria centrada no conceito de cultura como objeto de investigação, no estudo das representações sociais, das práticas culturais e do processo de apropriação, fundamentos centrais para a compreensão dos caminhos da profissionalização no momento da instituição da Lei n. 775, de 1949. A ancoragem teórica dessa escolha são os estudos ${ }^{(6-7)}$ que esclarecem as mudanças epistemológicas dessa corrente historiográfica. No processo de análise, também se trabalhou na perspectiva da $\mathrm{HC}^{(8)}$. Os demais teóricos utilizados na discussão deste artigo (re)contam a história da enfermagem e, direta ou indiretamente, focam as circunstâncias de oficialização da referida lei ${ }^{(2)}$.

A Escola de Enfermagem São Vicente de Paulo (EESVP) do Ceará, Brasil, foi o campo empírico deste estudo. É nas instituições de ensino que ocorre o encontro de diversas culturas, pois são ambientes nos quais o indivíduo tem a oportunidade de expressar sua cultura vivida $^{(9)}$. Diante das escolhas e orientações referidas acerca da $\mathrm{HC}$, decidiu-se focar a lente deste artigo no relacionamento da $\mathrm{HC}$ com as fontes e seu tratamento. Feitas estas considerações e nessa direção prioriza-se, metodologicamente, a pesquisa documental histórica. Consequentemente, o estudo apoia-se na análise de fontes documentais escritas ${ }^{(5-8)}$ e orais ${ }^{(10)}$.

Para instrumentalizar metodologicamente esta pesquisa, foram utilizadas fontes da EESVP, entre elas o programa de ensino da Enfermeira cearense de 1953-1963, que atendia acentuadamente à Lei n. 775, de 1949, e o programa de ensino da Auxiliar de Enfermagem, de 1954-1961, por ser o primeiro programa de ensino dessa categoria na referida escola.

Compreendeu-se que esses documentos escritos são monumentos ${ }^{(11)}$. A análise dos documentos escritos foi guiada por estudo sobre a operação historiográfica em temas regionais ${ }^{(8)}$. O percurso traçado para o desenvolvimento da pesquisa demandou que fontes orais fossem aliadas às fontes escritas, no intuito de complementar as informações e, sobretudo, ratificá-las quando necessário. Assim, foi tomada a palavra gravada de quatro professoras Enfermeiras da EESVP que tiveram inserção direta não somente junto ao curso de formação da Enfermeira, mas, sobretudo, no curso e ou programa de ensino da Auxiliar de Enfermagem, em Fortaleza (CE).

Para preservar a identidade das professoras entrevistadas, seus nomes foram substituídos por expressões nas quais se utilizou a letra E de Enfermeira (formação básica das entrevistadas), seguida do numeral cardinal da ordem em que ocorreu o primeiro contato com as entrevistadas. Exemplificando: E1 (Enfermeira e primeiro contato com a pesquisadora), E2 (Enfermeira e segundo contato com a pesquisadora) e assim sucessivamente. Após a recolha do documento sonoro que foi gravado e autorizado pelas professoras, realizou-se a análise do material colhido, conforme orientação contida em manual e História Oral ${ }^{12}$.

O estudo, extraído da tese de doutoramento intitulada Formação e Prática da Enfermeira 
Cearense: Implicações e Consequências da Implantação da Lei $n^{\circ} 775$ de 1949, defendida na Universidade Estadual do Ceará, em 2017, foi aprovado pelo Comitê de Ética e Pesquisa (CEP) da Universidade Estadual do Ceará, pelo Parecer n. 1.509 .938 .

\section{Resultados e Discussão}

Como forma de expressar os resultados e a discussão deste estudo, a princípio apresenta-se a comparação dos programas de ensino propostos pela "nova ordem" para a Enfermeira e a Auxiliar de Enfermagem cearenses, em especial dos programas de 1953-1963 da Enfermeira e de 1954-1961 da Auxiliar de Enfermagem da EESVP. Interessa pontuar que se toma a decisão, nesta pesquisa, de centrar as discussões nas disciplinas/unidades que tinham seus estágios vinculados à assistência hospitalar. Para tanto, apresenta-se o currículo completo das duas propostas formativas no Quadro 1. A opção por este foco de discussão e análise é fortalecida pelo fato de serem conteúdos típicos da formação para atuação de Enfermeiras e, sobretudo, de auxiliares dentro dos hospitais, uma vez que a "nova ordem" deixa claro que essa "nova categoria", no caso a Auxiliar de Enfermagem, iria atender as demandas desse campo.

Quadro 1 - Conteúdos teórico-práticos do programa de ensino da Enfermeira (1953-1963), expressos na primeira, segunda e terceiras séries, e da Auxiliar de Enfermagem (1954-1961). Escola de Enfermagem São Vicente de Paulo. Fortaleza, Ceará, Brasil

(continua)

\begin{tabular}{|c|c|c|c|}
\hline $\begin{array}{l}\text { Primeira Série/ano - } \\
\text { EESVP (1953-1963) }\end{array}$ & $\begin{array}{l}\text { Segunda Série/ano- } \\
\text { EESVP (1953-1963) }\end{array}$ & $\begin{array}{l}\text { Terceira série/ano- } \\
\text { EESVP (1953-1963) }\end{array}$ & $\begin{array}{l}\text { Programa de Ensino da Auxiliar de } \\
\text { Enfermagem da EESVP (1954-1961) }\end{array}$ \\
\hline $\begin{array}{l}\text { Técnica de } \\
\text { enfermagem ( } 430 \text { h) }\end{array}$ & - & - & Técnica de Enfermagem \\
\hline $\begin{array}{l}\text { Técnica de atadura } \\
(30 \mathrm{~h})\end{array}$ & - & - & Técnicas de ataduras \\
\hline $\begin{array}{l}\text { Anatomia e Fisiologia } \\
(180 \mathrm{~h})\end{array}$ & - & - & Anatomia \\
\hline $\begin{array}{l}\text { Higiene Individual } \\
(30 \mathrm{~h})\end{array}$ & - & - & Higiene e sua relação com a saúde \\
\hline $\begin{array}{l}\text { Ética/Ética } \\
\text { profissional }(30 \text { h) }\end{array}$ & - & $\begin{array}{l}\text { Ética }(30 \mathrm{~h}) \\
\text { Deontologia }(50 \mathrm{~h})\end{array}$ & Noções de ética \\
\hline $\begin{array}{l}\text { História da } \\
\text { enfermagem ( } 30 \text { h) }\end{array}$ & - & - & História da Enfermagem \\
\hline - & Pediatria $(90 \mathrm{~h})$ & Enfermagem pediátrica $(60 \mathrm{~h})$ & Enfermagem pediátrica \\
\hline $\begin{array}{l}\text { Nutrição e Dietética } \\
(30 \text { h) }\end{array}$ & $\begin{array}{l}\text { Dietética infantil }(30 \mathrm{~h}) \\
\text { Dietoterapia }(40 \mathrm{~h})\end{array}$ & - & Alimento e seu preparo \\
\hline Saneamento (30 h) & $\begin{array}{l}\text { Enfermagem nas doenças } \\
\text { transmissíveis }(70 \mathrm{~h}) \\
\text { Doenças transmissíveis } \\
(30 \mathrm{~h})\end{array}$ & $\begin{array}{l}\text { Enfermagem em Saúde } \\
\text { pública }(80 \text { h) } \\
\text { Higiene e Saúde pública } \\
(80 \text { h) }\end{array}$ & Enfermagem e Saúde pública \\
\hline- & $\begin{array}{l}\text { Enfermagem Obstétrica } \\
(80 \mathrm{~h})\end{array}$ & $\begin{array}{l}\text { Enfermagem Obstétrica } \\
(80 \mathrm{~h})\end{array}$ & Enfermagem Materno-infantil \\
\hline- & - & - & \\
\hline- & - & $\begin{array}{l}\text { Organização e administração } \\
\text { hospitalar (70 h) }\end{array}$ & \\
\hline - & - & $\begin{array}{l}\text { Enfermagem } \\
\text { Otorrinolaringológica }(30 \mathrm{~h})\end{array}$ & \\
\hline- & - & Obstetrícia (70 h) & \\
\hline- & - & Serviço social $(50 \mathrm{~h})$ & \\
\hline - & $\begin{array}{l}\text { Enfermagem de patologia } \\
\text { cirúrgica }(90 \mathrm{~h})\end{array}$ & - & \\
\hline $\begin{array}{l}\text { Drogas e soluções } \\
(30 \mathrm{~h})\end{array}$ & - & - & \\
\hline
\end{tabular}


Quadro 1 - Conteúdos teórico-práticos do programa de ensino da Enfermeira (1953-1963), expressos na primeira, segunda e terceiras séries, e da Auxiliar de Enfermagem (1954-1961). Escola de Enfermagem São Vicente de Paulo. Fortaleza, Ceará, Brasil

(conclusão)

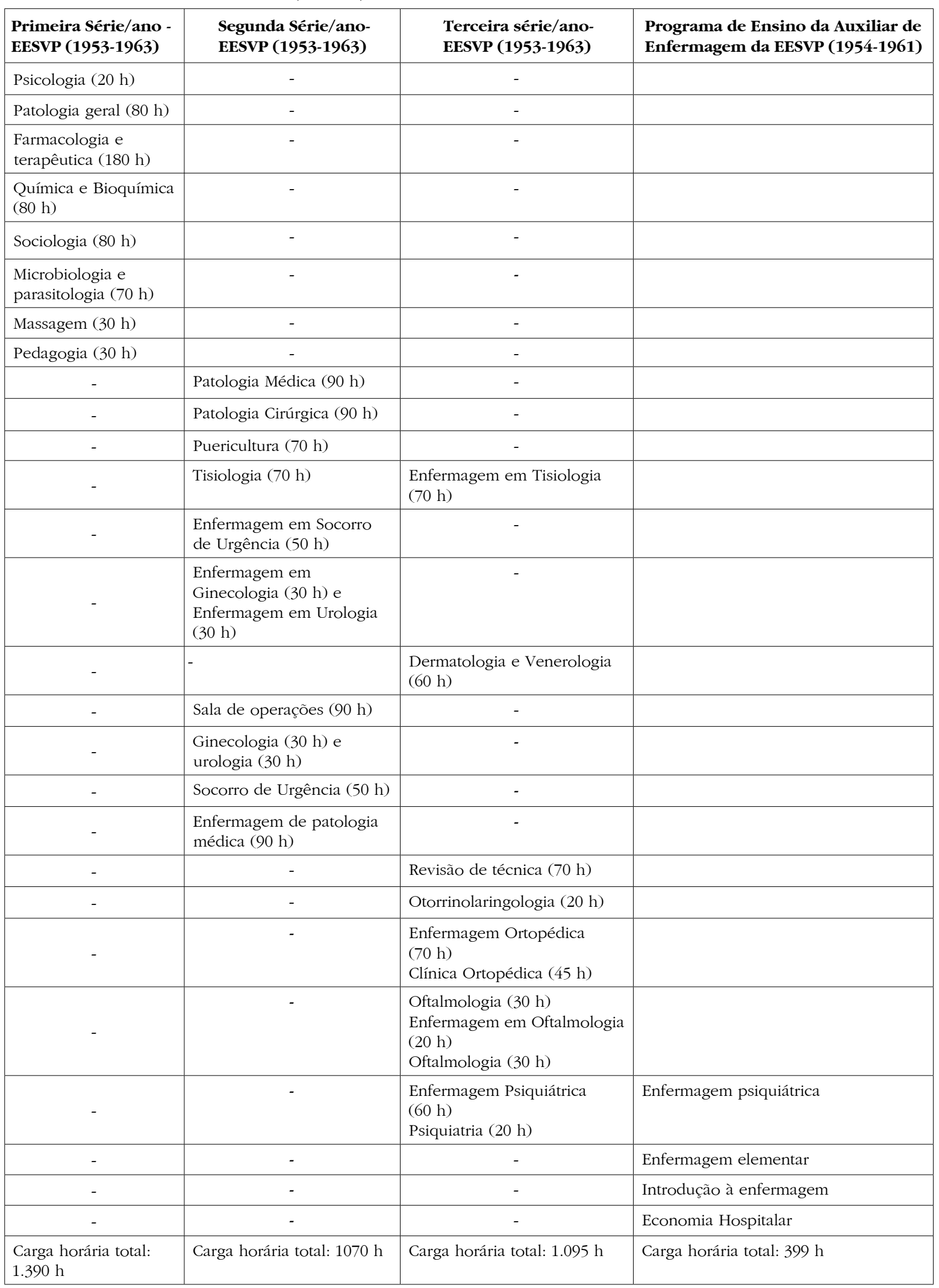

Fonte: Elaboração própria. 
Como se pode observar no Quadro 1, nove disciplinas eram ministradas à Auxiliar de Enfermagem cearense. Destas, oito - Técnica de enfermagem, Técnica de atadura, anatomia, higiene e seu relacionamento com a saúde, enfermagem pediátrica, enfermagem materno infantil, enfermagem psiquiátrica e alimento e seu preparo - apresentavam conteúdos voltados para assistência hospitalar e também eram ministradas à Enfermeira da EESVP. Dessas oito disciplinas similares nos dois programas analisados, cinco - Técnica de enfermagem, Técnica de atadura, anatomia, higiene e seu relacionamento com a saúde e alimento e seu preparo - aparecem na primeira série do curso para formação da Enfermeira. As outras duas aparecem na segunda e terceira séries com a denominação Pediatria (segunda série) e Enfermagem pediátrica e enfermagem psiquiátrica (terceira séria) e Enfermagem obstétrica (segunda e terceira série).

As disciplinas Técnica de Enfermagem e Técnica de atadura mantêm a mesma nomenclatura na primeira série/ano da Enfermeira e do programa de ensino da Auxiliar de Enfermagem, assim como Enfermagem Psiquiátrica, que aparece na terceira série da Enfermeira. Já outras matérias surgem com terminologias diferentes - embora se acredite que seus conteúdos eram similares.

Há uma evidência clara de repasse desses conteúdos ou a adaptação desse conjunto básico de matérias da Enfermeira para formar a auxiliar, embora se entenda que a proposta de formação dessa última profissional era mais elementar. Assim, em geral, os programas de ensino da EESVP, demonstrados e apresentados, mostram o modelamento do ensino da enfermagem para o atendimento das necessidades hospitalares que emergem no estado. Já o ensino da Auxiliar apresenta disciplinas que trazem nomenclaturas iguais ou aproximadas do curso da Enfermeira.

Quando se observa o Quadro 1, percebe-se que não há disposição de carga horária específica por disciplina na matriz curricular da Auxiliar de Enfermagem da EESVP (1954-1961). No entanto, é importante frisar que apenas uma das disciplinas relacionadas ao programa da
Enfermeira cearense era suficiente para superar a carga horária total do conteúdo teórico proposto para a Auxiliar de Enfermagem, no caso, a disciplina Técnica de enfermagem, por exemplo. Isso parece ser uma postura adotada pelas Enfermeiras da EESVP para firmar, de certa forma, o distanciamento entre as duas profissões, pelo menos no campo da formação para a assistência. Lembra-se que a Enfermeira brasileira e cearense, pela lei de 1949, tinha um ano a mais de formação do que a Auxiliar de Enfermagem, fato que imprimia, necessariamente, uma carga horária maior nesse programa de ensino. Contudo, no tocante ao conteúdo abordado nas disciplinas analisadas, pode-se dizer que o programa, embora sem delimitação clara, tratava praticamente os mesmos conteúdos, como comprovado pelas Enfermeiras entrevistadas, mas o grau de aprofundamento era diferenciado. A Professora E1 concorda com relação a essa questão:

\begin{abstract}
Elevávamos mais o nível teórico para a Enfermeira. Eram mais leituras e material escrito que existia na época para fundamentar a parte do ensino teórico para Enfermeiras. Diminuíamos a quantidade de aula e conteúdo para as Auxiliares. Assim, quando um mesmo assunto de disciplina que teria assistência hospitalar era ofertado a Enfermeira e a Auxiliar de Enfermagem da EESVP, acentuávamos a discussão teórica mais para a Enfermeira, uma vez que se reconhecia que a Auxiliar de Enfermagem só precisava ter conhecimento da técnica. (E1).
\end{abstract}

Tomando-se por base a fala de E1, observa-se que o nível de ensino, a escolaridade e a complexidade dos conteúdos para aprendizagem, sobretudo teórica, constituíam o parâmetro adotado ou lembrado pelas entrevistadas para estabelecer o distanciamento entre o que ensinar e ainda e principalmente até onde ensinar para a Enfermeira e para a Auxiliar de Enfermagem. Lembra-se que o nível de escolarização das Auxiliares de Enfermagem era elementar, uma vez que possuíam apenas o curso primário. Isto implica diretamente na capacidade de apreender conteúdos que seriam necessários somente na sua relação com a assistência a ser prestada. E3 confirma esse entendimento:

Agora, tinha uma coisa. As Auxiliares eram semianalfabetas. Não podíamos exigir muito. Senão, elas não acompanhavam o curso. (E3) 
Assim, houve um consenso, entre as quatro professoras entrevistadas, sobre o fato de que o campo de ensino ou as fronteiras entre a Enfermeira e o Auxiliar de Enfermagem constituía-se em pontos sistematizados, claramente reconhecidos, enquanto programas diferenciados por elas, como professoras.

As contradições, entretanto, entre sistematizar um programa de ensino e ensinar à Enfermeira e ao Auxiliar de Enfermagem, profissionais diferenciados por dispositivos legais (nova ordem) e, em função de sua escolarização formal, não se constituía em tarefa de fácil execução para aquela época (1949 a 1961). Até porque os recursos para a manutenção desses dois cursos na EESVP eram escassos. Sobre essa condição de sistematizar o que ensinar e até onde ensinar, o que se observa, principalmente, é que esse limite ou separação encerrava também componentes subjetivos relacionados à percepção de cada professora.

Acredita-se que a condição anunciada não parece ter sido tão simples para as professoras da época. Até porque, as atribuições desses estratos não eram claramente definidas em 19491961, especialmente pelo histórico prematuro da profissão no país. Isso, entretanto, não invalida dizer que havia certa preocupação das Enfermeiras pioneiras dessa profissão no país referente a esta questão (Enfermeira X Auxiliar) especialmente no eixo Rio-São Paulo. Outros autores $^{(2)}$ comprovam essa preocupação, ao discutirem as circunstâncias que determinaram a inclusão do Auxiliar de Enfermagem na Lei n. 775/49. Com a finalidade de discutir e deliberar sobre os problemas da Enfermagem brasileira, a diretora da Escola de Enfermagem D. Anna Neri, Dra. Lays Netto dos Reys, a partir de 1943 e até o ano de 1946, tomou a iniciativa de reunir as diretoras de escolas de enfermagem em funcionamento. Um dos assuntos mais polêmicos foi justamente a questão da insuficiência de pessoal de enfermagem e as alternativas para ampliar esse número sem abalos à qualidade da formação das Enfermeiras. Esses assuntos foram discutidos entre os anos de 1944 a 1946.
Diante dessas questões, as Enfermeiras diplomadas decidiram propor à Associação Brasileira das Enfermeiras Diplomadas que assumisse a direção dos trabalhos quanto à proposta e acompanhar de perto o texto da lei em estudo. Isso, particularmente, impacta diretamente nas distinções expressas do que ensinar à Enfermeira e à Auxiliar de Enfermagem. Obviamente, essas discussões chegavam às escolas de todo Brasil.

Entretanto, autores ${ }^{(13)}$ argumentam que as disciplinas ministradas às Auxiliares de Enfermagem nos mais diversos cursos do país eram insuficientes para transmitir-lhes as informações que realmente necessitavam, uma vez que as Auxiliares vinham exercendo atividades mais complexas que as previstas no ensino e, na maior parte das vezes, as executavam sem a orientação da Enfermeira. O que, de certo modo, demonstra que as funções que as Auxiliares de Enfermagem vinham desenvolvendo no campo hospitalar eram aproximadas ou similares às realizadas pela Enfermeira e, de certa forma, a proposta pensada pelo quadro maior da Enfermagem brasileira, como forma de garantir o distanciamento entre as duas profissões, não estava atendendo às expectativas.

Assim, o caminho de profissionalização da Enfermeira, com a "nova ordem", precisou ser redirecionado ou reconstruído num cotejo lento que envolveu uma caminhada longa, outras lutas e algumas conquistas nessa busca de profissionalização. Resultados mais concretos só foram alcançados no início da década de 1960, com a reforma do ensino superior e a entrada da Enfermagem como curso universitário. Fortaleceu-se, sobretudo, nas décadas de 1970 e 1980, especialmente com a criação e implantação do Conselho Federal de Enfermagem (Lei n. 5.905, de 1973), a criação dos códigos de Deontologia de Enfermagem (Resolução COFEN n, 9, de 1975), o Processo Ético (Resolução COFEN n. 10, de 1975) e de Transgressões e Penalidades (Resolução CONFEN n. 19, de 1975) e, posteriormente, a Lei do exercício profissional (Lei n. 7.498, de 1986).

É importante lembrar que o cenário à época tinha um contingente limitado de Enfermeiras e presença mais prevalente de Auxiliares de 
Enfermagem. Isto, de certo modo, conduziu a tomarem para si as atribuições específicas da Enfermeira, alicerçadas na formação e nos fundamentos para sua realização, assim como acontecia a apropriação pela falta de profissionais. Com relação a esta questão, uma das Enfermeiras entrevistadas, a professora E1, que por muito tempo (1965 a 1976) foi Coordenadora do curso de Auxiliar de Enfermagem da EESVP, e também a professora $\mathrm{E} 4$, referem:

Como elas dividiam o mesmo espaço no bospital, a Enfermeira começava a demarcar alguns espaços de atuação. Em geral, a aluna Enfermeira fazia as funcôes que considerava mais administrativa, como observação e relatórios. Era difícil uma Enfermeira formada pegar no pesado. As primeiras Enfermeiras diplomadas no Ceará não queriam fazer certas coisas. Achavam-se muito importantes porque eram as Enfermeiras Ana Neri. Então, a Auxiliar fazia tudo, principalmente o mais pesado na unidade e com o paciente. (E1).

O que era interessante à época é que elas [Auxiliares de Enfermagem] sabiam que espaço ocupar. Era muito difícil uma aluna Enfermeira ir dá banbo no leito. Assim como tínhamos alunas Auxiliares que limpavam até o chão. (E4).

Outras professoras entrevistadas trazem, em suas falas, a dimensão dos conflitos internos, não só na divisão de tarefas no campo hospital, mas em outros espaços de convivência, quando assinalam:

As primeiras Enfermeiras formadas pela escola não queriam realizar certas coisas, como extração de urina, asseio do paciente, banbo no leito, por exemplo. Se achavam superiores às Auxiliares, porque eram Enfermeiras Ana Neri. (E1).

Essa fala remete à constatação de uma posição, observada no campo de prática, que vai distanciando consciente ou inconscientemente a Enfermeira cearense de alguns cuidados junto ao paciente. De forma gradativa, entende-se que ela se exime de muitos outros cuidados, de certa forma alicerçada no aumento cada vez maior do contingente de Auxiliares de Enfermagem no mercado de trabalho, sobretudo o hospitalar, em detrimento do número crescente de Enfermeiras formadas, mas em escala muito inferior.

Entende-se também que o afastamento da Enfermeira dos cuidados junto ao paciente configura uma forma de busca de diferenciação entre suas funções e as da Auxiliar. O contexto contribuía igualmente para que ela assumisse essa posição, que a colocava cada vez mais distante do cuidado. Inclusive, na década de 1980, ela já assinalava que esse foi um lugar (assistência direta) que nunca de fato foi ocupado por essa profissional $^{(14)}$. Isto, de certa forma, fortalece o que se coloca como consequência da implantação da "nova ordem".

Essa busca da Enfermeira pela diferenciação em pequenos espaços, sobretudo na assistência prestada no campo hospitalar, termina por aproximá-la cada vez mais das atividades de supervisão e administração (detalhada a seguir), o que vai se fortalecer na profissão com o passar do tempo. Assim, o objeto da enfermagem (assistência e cuidado) fragmenta-se entre manual e intelectual, e este último constitui-se na principal tarefa da Enfermeira. Nesse sentido, estudo ${ }^{(15)}$ que reflete sobre a prática da enfermagem contribui nesta discussão, quando assinala que, no final da década de 1970, esse distanciamento do cuidado direto só se agrava: "As funções desempenhadas pela Enfermeira caracterizam, destarte, uma supervalorização dos aspectos administrativos e de supervisão do pessoal auxiliar, em detrimento dos aspectos técnicos assistenciais, apesar de serem estes que evidenciam perícia e evidência" ${ }^{(15: 104)}$. Outro fator importante e inerente a esta questão foi a busca da Enfermeira por espaço, reconhecimento e poder.

Todo esse movimento teve como consequência, consoante estudo(16) ${ }^{(16)}$ analisa criticamente a enfermagem profissional, que a Enfermeira, 24 anos após a nova ordem, cônscia de seu status e elevado nível de instrução, não prestava mais cuidados aos enfermos. O que teria ocorrido com a institucionalização desses papéis? - questiona a autora. A resposta para essa pergunta requer a compreensão de que,

\footnotetext{
[...] a assistência de enfermagem é a razão de ser da enfermagem em seu conjunto, mas a realização necessita de uma série de atividades que não são específicas de enfermagem, embora para ela esteja voltada. Este fato é responsável, penso, para problemática do status-papel da Enfermeira, em cujas raízes se encontra o dilema cuidado direto $\mathrm{x}$ cuidado indireto ${ }^{(16: 86)}$.
}

Dito isto, ainda se coloca que as circunstâncias de oficialização do curso de Auxiliar de 
Enfermagem no Brasil exigiram das Enfermeiras outras alternativas que pudessem garantir as distinções entre essas duas categorias profissionais, especialmente no Ceará, uma vez que a EESVP tratou de empregar símbolos ou representações objetais para sanar essa confusão, entre eles o uso de uniforme pelas alunas Auxiliares diferenciados da Enfermeira. A propósito dessa iniciativa, as professoras E1, E2 e E3 relembram:

O paciente diferenciava a Enfermeira da Auxiliar de Enfermagem pelo uniforme. (E1).

Tinhamos a presença do uniforme mais elegante para Enfermeira. (E3).

Inovamos neste quesito. Foi pensada uma roupa diferente. Um branco creme para Auxiliar de Enfermagem. (E2).

A primeira vestimenta usada pelas Auxiliares no estado do Ceará era de um tecido na cor creme, passando depois a ser na cor azul claro. Isto, do ponto de vista das Enfermeiras da EESVP, poderia facilitar a correlação da imagem da Auxiliar de Enfermagem como figura distinta da Enfermeira. Entende-se que à época, por questões já explicitadas, não era fácil distinguir dois membros distintos dentro da profissão, daí o reconhecimento de uma só imagem e identificação de uma só profissão ou profissional. A adesão a esse tipo de uniforme reflete a elaboração de um grupo de ideais-imagens construído pelas Enfermeiras do Ceará, a fim de estabelecer distinções entre a Enfermeira e a Auxiliar de Enfermagem no estado.

Dessa forma, importa assinalar que havia duas imagens concorrentes no período da nova ordem no Ceará - a Enfermeira e a Auxiliar de Enfermagem - que mantinham um nexo com a prática do cuidar, o que leva a considerar certa aproximação, vinculada ao público, por ações que se mesclavam. Isso imprimia necessariamente situações confusas entre as duas profissões, até porque não havia legislação do exercício profissional até 1961.

Essa projeção de imagem vai perpassar pelo longo percurso histórico da profissão, configurando uma única imagem aos olhos do paciente e consequentemente da sociedade. Após 24 anos da implantação da "nova ordem", e já sob a presença da legalização do exercício profissional pelo Decreto n. 50.387, de 1961, ainda se afirmava que, para o paciente, principalmente o de escolaridade mais elementar, havia poucas oportunidades para diferenciar a Enfermeira das Auxiliares de Enfermagem ${ }^{(17)}$.

Esse entendimento também é compartilhado por pesquisadores ${ }^{(17)}$, em estudo realizado em 2007, ao identificarem que, 58 anos após a nova ordem, a ambiguidade da denominação profissional ainda se mantinha, induzindo a compreensão de que toda mulher que vestia uniforme branco e caminhava nos corredores dos hospitais era identificada como Enfermeira. Assim, como a imagem remete à identidade profissional, as reformulações nas regras de ensino da enfermagem ou o aceite da nova ordem no Ceará significou uma caminhada em direção a uma nova reconfiguração profissional da Enfermeira da EESVP. E o campo prático dificultava enormemente essa distinção, por razões já explicitadas.

Então, entende-se que inconscientemente, como forma de garantir um projeto identitário de profissão e poder, a Enfermagem cearense, no período de 1954-1961, buscou alternativas de reconhecimento social, cristalizando uma organização heterogênea e fragmentada da profissão, distanciando-se da função pela qual é reconhecida: a assistência, o cuidado. Percebe-se que a "nova ordem" trouxe essa consequência para a profissão (uma das) e teve implicações que ainda repercutem nos tempos recentes de atuação desse profissional.

Feitas essas ponderações, aponta-se como limitação do estudo a participação de apenas quatro Enfermeiras entrevistadas. Entretanto, entende-se que a vivência intensa das Enfermeiras do estudo no processo de implantação do curso cearense facilitou a recolha de informações que possibilitaram o alcance do objetivo proposto.

\section{Conclusão}

O artigo sustenta que a situação embrionária da formação e prática da Enfermeira cearense, no período de 1949-1961, instala uma crise na 
profissão, na medida em que duas profissões passam a ter o mesmo objeto de trabalho, no caso o cuidado. A Enfermeira cearense, no campo hospitalar sobretudo, busca estratégias para se distanciar da Auxiliar de Enfermagem, afastando-se do cuidado direto e aproximando-se crescentemente das atividades de administração e supervisão. Utilizando-se também de representações objetais, no caso, a instituição de uniformes pela EESVP, em uma tentativa de diferenciar a Auxiliar de Enfermagem, adotou uma posição que se mostrou sinuosa e não conseguiu definir os campos e as diferenças, à época. Essa condição instala, no interior da profissão, o reconhecimento de uma só imagem e a identificação de uma só profissão ou profissional, especialmente pelo paciente. A projeção de uma única imagem implica diretamente na identidade da Enfermeira, assim como em seus espaços de prática e poder.

Logo, diante dos resultados obtidos, também se chega a um ponto de nova partida, quando se sugere que estudos futuros voltem à temática, especialmente no que se refere à visão que a existência da Auxiliar de Enfermagem possibilitou, em decorrência exclusiva da exigência do mundo do trabalho, ainda que essa não seja a real justificativa. Com a promulgação da Lei n. 775, de 1949, também se transformou, além da formação, o objeto de atuação da Enfermeira no Brasil e, consequentemente, no Ceará.

\section{Colaborações:}

1. concepção, projeto, análise e interpretação dos dados: Roberlandia Evangelista;

2. redação do artigo e revisão crítica relevante do conteúdo intelectual: Silvia Maria Nóbrega-Therrien;

3. aprovação final da versão a ser publicada: Carlos Romualdo de Carvalho e Araújo.

\section{Referências}

1. Fonte AS. A Escola de Enfermagem Anna Nery e a nova ordem no campo da educação em enfermagem: (1949-1961) [tese]. Rio de Janeiro;
Escola de Enfermagem Anna Nery, Universidade Federal do Rio de Janeiro; 2009.

2. Santos RM, Trezza MCSF, Candiotti ZMC, Leite JL. Circunstâncias de oficialização do curso de auxiliar de enfermagem no Brasil: estudando as entrelinhas da Lei 775/49. Rev Latino-Am Enfermagem. 2002;10(4):552-60.

3. Pestana BR, Pessoa SB. Leishmaniose tegumentar autóctone no município de São Paulo. Annaes Paul Med Cirurg. 1940;40(1):71-2.

4. Nóbrega-Therrien SM, Almeida MI, Lopes RE, Silva AC, Mendes ETB, Gonçalves SES, et al. Keeping the light on - Nursing history center in Ceara NUDIHMEn. Rev Bras Enferm. 2018;71(5):2579-83.

5. Lopes RE, NóbregaTherrien SM, Aragão SB. Estudos sobre o impacto da lei número 775 na formação da enfermeira. Hist enferm Rev eletronica [Internet]. 2016 [cited 2018 Jan 27];7(2):449-57. Available from: http://here.abennacional.org.br/here/2a07.pdf

6. Burke P. O que é História Cultural? Tradução Sergio Goes de Paula. 2a ed. Rio de Janeiro: Jorge Zahar; 2008.

7. Pesavento SJ. História \& história cultural. 2a ed. Belo Horizonte: Autêntica; 2005.

8. Luchese TA. Modos de fazer história da educação: pensando a operação historiográfica em temas regionais. História da Educação. 2014;18(43):145-61.

9. Almeida ECR. História da Escola de Enfermagem Madre Justina Inês: uma instituição de ensino superior formando enfermeiras em Caxias do Sul/RS (1957-1967) [dissertação]. Caxias do Sul: Universidade de Caxias do Sul; 2012.

10. Almeida ZCM. Educação e memória: velhos mestres de Minas Gerais (1924-1944) [tese]. Brasília: Universidade de Brasília; 2009.

11. Le Goff J. História e memória. Campinas: Editora Unicamp; 1996.

12. Alberti V. Manual de história oral. 3a ed. Rio de Janeiro: Fundação Getúlio Vargas; 2005.

13. Monteiro BA, Oguisso T. Visão histórica da Lei $\mathrm{n}^{\mathrm{o}} 775$ de 1949 e seu impacto no ensino de enfermagem no Brasil. In: Oguisso T, Freitas GF. História da Enfermagem: instituições e práticas de Ensino e Assistência. Rio de Janeiro: Águia Dourada; 2015. p. 31-45.

14. Melo CB. Ensino de psicologia na Escola de Enfermagem Carlos Chagas (1933-1962) 
[dissertação]. Belo Horizonte: Universidade Federal de Minas Gerais; 2010.

15. Carvalho V, Castro IB. Reflexões sobre a prática da Enfermagem. Trabalho apresentado no $31^{\circ}$ Congresso Brasileiro de Enfermagem; 1979 out 5-11; Fortaleza, CE, Brasil. Anais (online) Brasília (DF): SESU/MEC; 1999 [cited 2018 Jan 27]. Available from: https://scholar.google. $\mathrm{com} /$ scholar_lookup?title $=$ Reflex\%C3\%B5es + sobre+a+Pr\%C3\%A1tica+da+Enfermagem+ Anais\&author $=$ Carvalho + V\&author $=$ Castro
+ I B \& publication_ye a r $=1999 \&$ pages $=51-59$

16. Silva GB. A enfermagem profissional: uma análise crítica. São Paulo: Cortez; 1986.

17. Nóbrega-Therrien SM, Almeida MI. Enfermeira, profissão, saberes e prática: potencialidades, limites e possibilidades. Fortaleza (CE): EdUECE; 2007.

Recebido: 1 de junho de 2018

Aprovado: 30 de outubro de 2018

Publicado: 27 de dezembro de 2018

A Revista Baiana de Enfermagem utiliza a Licença Creative Commons - Atribuição-NãoComercial 4.0 Internacional.

https://creativecommons.org/licenses/by-nc/4.0/

Este artigo é de acesso aberto distribuído sob os termos da Licença Creative Commons (CC BY-NC).

Esta licença permite que outros remixem, adaptem e criem a partir do seu trabalho para fins não comerciais. Embora os novos trabalhos tenham de lhe atribuir o devido crédito e não possam ser usados para fins comerciais, os usuários não têm de licenciar esses trabalhos derivados sob os mesmos termos. 